\title{
VEÍCULOS ALEGÓRICOS EM CRÔNICAS MACHADIANAS E EM NOVECENTO, DE ALESSANDRO BARICCO
}

\author{
Roberta Mataragi \\ Mestranda do Curso de Pós- Graduação em Literatura - UFSC
}

\begin{abstract}
RESUMO
Tendo como pressuposto teórico a concepção de alegoria de Walter Benjamin, pretende-se realizar no seguinte ensaio a leitura alegórica de dois meios de transportes: o bonde, presente em algumas crônicas de Machado de Assis, e o navio Virginian, transatlântico da ficção italiana Novecento, un monologo, de Alessandro Baricco. Toma-se o bonde como veículo alegórico partindo das considerações de Ana Luiza Andrade que o pensa como o transporte da própria crônica, e observa-se que existe uma semelhança no tocante a existência do transatlântico da ficção italiana também como um veículo que não somente transportava passageiros, mas suas histórias de vidas. Portanto, ambos podem ser pensados como veículos alegóricos significativos do próprio contexto histórico dos séculos XIX e XX, respectivamente.
\end{abstract}

\section{PALAVRAS-CHAVE}

Alegoria; Crônica; Ficção.

\section{ALLEGORICAL VEHICLES IN MACHADO DE ASSIS' CRÔNICAS AND IN ALESSANDRO BARICCO'S NOVECENTO}

\section{KEYWORDS}

Allegory; Crônicas; Fiction.

\section{ABSTRACT}

Taking Walter Benjamin's concept of allegory as a theoretical basis, this essay aims at carrying out an allegorical reading of two means of transportation: the streetcar, present in some Brazilian writer Machado de Assis' crônicas (short literary commentaries on facts of daily life), and the ship Virginian, from Italian fictional story Novecento, un monologo, by Alessandro Baricco. The streetcar is considered an allegorical vehicle, in accordance with the ideas of Ana Luiza Andrade, who sees it as a means of transportation for the cronica itself. It is possible to think of a similarity with the Italian fictional ship, which was also a vehicle that conveyed not 
only passengers, but also their life stories. Therefore, both of them can be thought of as allegorical vehicles representing the historical context of nineteenth and twentieth centuries, respectively.

No seguinte ensaio, convido o leitor a realizar uma leitura alegórica de dois meios de transporte: o bonde presente nas crônicas de Machado de Assis, analisadas por Ana Luiza Andrade em "Passagens de Bond, com Machado"1, e o transatlântico Virginian, em Novecento - un monologo, de Alessandro Baricco², como "veículos alegóricos" que não somente transportavam os passageiros e suas histórias, mas também significavam a própria história.

Como referente teórico, partirei da concepção de alegoria de Walter Benjamin. ${ }^{3}$ Em nota introdutória, Rouanet explica o conceito de alegoria como linguagem no Barroco. O tradutor aborda o termo alegoria pelo significado etimológico: alegoria deriva de allos (outro) e agoreuein, falar na ágora (usar uma linguagem pública). Expressar-se alegoricamente significa usar uma linguagem literal, compreensível a todos, com o intuito de se remeter a um outro nível de significação. Seria como se referir a "uma coisa para significar outra". ${ }^{4}$ Partindo da explicação etimológica, Rouanet intenciona esclarecer a interpretação do conceito benjaminiano de alegoria. A linguagem alegórica barroca consiste em significar a própria concepção barroca da história. O pensamento histórico do Barroco entendia a história como natureza selvagem e a política como uma prática de naturalização da história. A morte é o conteúdo mais abrangente da alegoria barroca, pois significa a história-destino que é tida como a verdade última da vida; a morte concebida como "o extremo em que o homem sucumbe à sua condição de criatura."

Ana Luiza Andrade pensa o bonde nas crônicas machadianas como o transporte alegórico da própria crônica. Desenvolve tal pensamento expondo que "a ambivalência da crônica como forma de produção jornalística, ao ligar-se (que em inglês é estar bonded) e ao desligar-se (como é o caso do burro) à nova tecnologia, revela-se no transporte que se faz alegórico da própria crônica como elo, ou liga locomotora." 6

\footnotetext{
ANDRADE, Ana Luiza. Passagens de Bond, com Machado. Travessia 33. Revista de Literatura da Pós-Graduação, EDUFSC, 1996.

BARICCO, A. Novecento: un monologo. Torino: Angolo Manzoni, 2000a.

BENJAMIN, W. Origem do drama barroco alemão. Trad. Sérgio Paulo Rouanet. São Paulo: Braziliense, 1984.

Op. cit., p. 37.

Ibid., p. 38.

ANDRADE, Ana Luiza. Passagens de Bond, com Machado. Travessia 33. Revista de Literatura da
} 
Retomando algumas características das crônicas machadianas apontadas por Andrade, temos a importante informação de que a crônica foi uma invenção recente do fim do século XIX, a qual participou de forma violenta de movimentos significativos de passagem de uma sociedade moderna, "transformando-se" em meio de transporte para o entrecruzamento dos processos sociais, históricos, políticos e econômicos que foram desencadeados culturalmente na época. Dentre eles identificamos certamente os movimentos do setor público ao privado, da monarquia à república e o movimento gritante entre as classes sociais que projeta uma imagem de otimismo, de um futuro promissor, mas resulta na mais absoluta miséria, tanto cultural quanto econômica. A atenção de Machado de Assis está voltada às minúcias, ao que é descartado, "ao que se desterritorializa no processo do movimento, nesta passagem da ordem do dia para a noite do obscurantismo, o que se perde entre a construção e a destruição, chegando ao próprio ser humano, em seu corpo orgânico e animal, entre os seus extremos culturais e suas fronteiras naturais."7

Nas crônicas machadianas, o movimento cultural desterritorializador da mecanização está inscrito no momento da novidade da introdução dos bondes elétricos no Rio de Janeiro. Agradecidos a Andrade pela condução das informações contextualizadoras sobre os movimentos desterritorializadores, embarquemos agora nos bonds já inaugurados e notemos como podem ser entendidos como veículos alegóricos. Transportam passageiros, informações e, ao mesmo tempo, são eles mesmos informações representativas; significam a encarnação da própria história: "Inauguram-se os bonds de Santa Teresa, - um sistema de alcatruzes ou de escada de Jacó, - uma imagem das coisas deste mundo. ${ }^{\prime 8} \mathrm{E}$ atentemos, do outro lado, ao movimento da chegada do progresso trazendo o des-emprego dos burros no transporte dos bondes. “Alguns burros, [...] estavam ontem lastimando o novo passo do progresso. [...] E esse quadrúpede olhava para o bond com um olhar cheio de saudade e humilhação." ${ }^{9} \mathrm{E}$ conduzidos agora pela opinião certeira de Machado de Assis, confirmamos os confortos e desconfortos que o progresso nos proporcionou, e ainda hoje, nos proporciona, pelo aprimoramento das modernas tecnologias: "Talvez rememorava a queda lenta do burro,

Pós-Graduação, EDUFSC, 1996, p. 99.

7 Ibid. p. 98.

8 MACHADO DE ASSIS. Fragmento III de História de 15 dias (15 de março de 1877). In: -

- Obra Completa, vol. III, Rio de Janeiro: Nova Aguilar, 1994. Disponível em: $<$ http://www.cce.ufsc.br/ nupill/literatura/quinze.html>. Acesso em: 13 ago 2009. Grifo meu. 9 Ibid. 
expelido de toda parte pelo vapor, como o vapor o há de ser pelo balão, e o balão pela eletricidade, a eletricidade por uma força nova, que levará de vez este grande trem do mundo até à estação terminal. [...] Mas inauguram-se os bonds." 10

O bonde elétrico nos conduz ao pensamento dele mesmo como veículo alegórico representativo da eletricidade como a agilidade, a rapidez oferecida pelo advento das locomoções modernas, a qual deveria estar presente também no comportamento humano. Haveria de se tomar atitudes rápidas, mecanizadas. Sem muito pensar, filosofar, como fazem os estudantes vadios.

\begin{abstract}
Uma das vantagens dos bonds de Santa Teresa sobre os seus congêneres da cidade, é a impossibilidade da pescaria. A pescaria é a chaga dos outros bonds. [...]; cada bond desce a passo lento, a olhar para um e outro lado, a catar um passageiro ao longe. Às vezes o passageiro aponta na Praia do Flamengo, o bond, polido e generoso, suspende o passo, cochila, toma uma pitada, dá dois dedos de conversa, apanha o passageiro, e segue o fadário até a seguinte esquina onde repete a mesma lengalenga.

Nada disso em Santa Teresa: ali o bond é um verdadeiro leva-e-traz; não se detém a brincar no caminho como um estudante vadio. ${ }^{11}$
\end{abstract}

Levando e trazendo a idéia central da mecanização resultante do movimento da tração animal à tração elétrica, notamos como, de fato, o ser humano incorporou o sentimento desejado pelo progresso que nos trouxe o poder da eletricidade. No comportamento do cocheiro do bond elétrico, transparecia a superioridade que julgava ter em relação ao bond puxado pelos burros:

\begin{abstract}
Anteontem, porém, indo pela Praia da Lapa, em um bond comum, encontrei um dos elétricos, que descia. Era o primeiro que estes meus olhos viam andar.

Para não mentir, direi que o que me impressionou, antes da eletricidade, foi o gesto do cocheiro. Os olhos do homem passavam por cima da gente que ia no meu bond, com um grande ar de superioridade. Posto não fosse feio, não eram as prendas físicas que lhe davam aquele aspecto. Sentia-se nele a convicção de que inventara, não só o bond elétrico, mas a própria eletricidade. Não é meu ofício censurar essas meias glórias, ou glórias de empréstimo, como the queiram chamar espíritos vadios. As glórias de empréstimo, se não valem tanto como as de plena propriedade, merecem sempre algumas mostras de simpatia. Para que arrancar um homem a essa agradável sensação? Que tenho para lhe dar em troca? Em seguida, admirei a marcha serena do bond, deslizando como os barcos dos poetas, ao sopro da brisa invisível e amiga. Mas, como íamos em sentido contrário, não tardou que nos perdêssemos de vista, dobrando ele para o Largo da Lapa e Rua do Passeio, e entrando eu na Rua do Catete. Nem por isso o perdi de memória. A gente do meu bond ia saindo aqui e ali, outra gente entrava adiante do fim da linha e já noite, éramos só três pessoas, o condutor, o cocheiro e eu. Os dous
\end{abstract}

10 Ibid.

11 MACHADO DE ASSIS. Fragmento III de História de 15 dias (15 de março de 1877). In:

- Obra Completa, vol. III, Rio de Janeiro: Nova Aguilar, 1994. Disponível em:

$<$ http://www.cce.ufsc.br/ nupill/literatura/quinze.html $>$. Acesso em: 08 ago 2009. 
cochilavam, eu pensava. ${ }^{12}$

E se aproveitarmos para admirar também a marcha serena dos barcos dos poetas, descermos do bond de Machado de Assis, do século XIX, e subirmos a bordo do transatlântico Virginian, de Alessandro Baricco, do século XX, em Novecento $^{13}$, notaremos que ele pode ser interpretado como veículo alegórico de maneira semelhante ao bonde. Em movimentos diferentes de desterritorialização, pois está inserido em um contexto histórico com deslocamentos e passagens de tempo e espaço outros.

Apresento aos que prosseguem, o Virginian: esse transatlântico realizava viagens entre a Europa e a América desde o início do século XX até a Segunda Guerra Mundial, transportando tanto passageiros milionários como emigrantes. Nele se exibia todas as noites um pianista extraordinário, capaz de tocar uma música jamais ouvida. Sua história de vida era inacreditável, pois diziam que tinha nascido naquele navio, de onde nunca descera, mas ninguém sabia o porquê. Seu nome era Danny Boodmann T. D. Lemon Novecento. Provavelmente filho de emigrantes, havia sido deixado dentro de uma caixa de limões sobre o piano de cauda do salão de baile do navio. Encontrado por um marinheiro, teve tudo de melhor que este lhe pudesse oferecer, inclusive o nome, que o pai adotivo julgou importante de modo a lhe atribuir uma identidade: Danny Boodmann T. D. Lemon Novecento, este último nome em homenagem ao século que se iniciara, pois Novecento é como é chamado o século XX em italiano. A referida narrativa tem como narrador-personagem o trompetista componente da banda do navio, grande amigo de Novecento, Tim Tooney.

Envolvidos pelo contexto histórico e ficcional referente à narrativa italiana de Baricco, voltemos nossa atenção às narrativas que circulam como informações e juntas compõem a idéia central significada pelo veículo alegórico tal como pensaremos o transatlântico. No Virginian transitam passageiros que viajam da Europa para América e

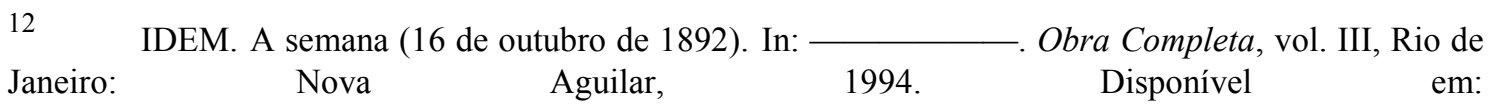
http://www.cce.ufsc.br/ nupill/literatura/semana.html. Acesso em: 08 ago 2009.

13 Novecento: un monologo foi escrito originalmente na forma de um monólogo teatral e interpretado por Eugenio Allegri, da Compagnia Teatro Settimo, sob a direção do próprio Baricco e de Gabrielle Vacis. Posteriormente, o diretor italiano Giuseppe Tornatore adaptou a obra para o cinema, sob o título La leggenda del pianista sull'oceano, lançado no Brasil como A lenda do pianista do mar. Em 1994 a narrativa foi publicada pelo autor em forma de livro. Apesar de ter sido escrito como monólogo em sua primeira versão, o próprio autor declara no prólogo do livro que não sabe se esse fato é suficiente para dizer que se trate de um texto teatral; mais ainda, afirma duvidar disso. Relata que, quando viu a obra em forma de livro, pareceu-lhe mais um texto entre uma cena a ser representada e uma história para ser lida em voz alta. Neste trabalho, adotarei a narrativa da obra em forma de texto literário, e não como encenação teatral. 
trazem consigo toda a história de suas terras natais, informações que se fazem presentes na própria situação do deslocamento de cruzar oceanos em busca de condições melhores de vida na América. Consideremos as crises econômicas, as guerras mundiais, a esperança de fazer fortuna em solo americano. Essas situações propiciaram o processo do movimento tendo como resultante a desterritorialização que poderemos identificar nos exemplos das histórias dos passageiros em busca da promissora América, na formação discursiva e musical do pianista Novevento e do narrador-personagem.

Succedeva sempre che a un certo punto uno alzava la testa... e la vedeva. $\grave{E}$ una cosa difficile da capire. Voglio dire... Ci stavamo in più di mille, su quella nave, tra ricconi in viaggio, e emigranti, e gente strana, e noi... Eppure c'era sempre uno, uno solo, uno che per primo... la vedeva. Magari era li che stava mangiando, o passeggiando, semplicemente, sul ponte... magari era lì che si stava aggiustando i pantaloni... alzava la testa un attimo, buttava un occhio verso il mare... e la vedeva. Allora si inchiodava, li dov'era, gli partiva il cuore a mille, e, sempre, tutte le maledette volte, giuro, sempre, si girava verso di noi, verso la nave, verso tutti, e gridava (piano e lentamente): l'America. Poi rimaneva li, immobile come se avesse dovuto entrare in una fotografia, con la faccia di uno che l'aveva fatta lui l'America. $^{14}$

Acontecia sempre que alguém, a certa altura, levantava a cabeça... e a via. É uma coisa difícil de entender. Quero dizer... Éramos mais de mil, naquele navio, entre ricaços em viagem e emigrantes, e gente estranha, e nós... E no entanto havia sempre um, um só, um que primeiro... a via. Talvez estivesse ali comendo, ou passeando, simplesmente, na ponte... talvez estivesse ali ajeitando as calças... levantava por um instante a cabeça, lançava um olhar ao mar... e a via. Então ficava imóvel, ali onde estava, partia-lhe o coração em mil pedaços e sempre, todas as malditas vezes, juro, sempre, virava-se para nós, para o navio, para todos, e gritava (baixo e lentamente): a América! Depois permanecia ali, imóvel como se devesse fazer parte de uma fotografia, com cara de quem a tivesse feito, a América. ${ }^{15}$

Tendo nascido e crescido dentro do navio, Novecento conhecia o mundo pela narrativa dos passageiros que por ali passavam. Construía sua "visão do mundo" a partir das informações dos passageiros; da leitura dos mesmos. Sabia ler as pessoas, os sinais que cada um carrega, lugares, barulhos, cheiros, a história de sua terra. E a cada dia juntava um pedaço ao imenso mapa que estava desenhando na própria cabeça; o mapa do mundo.

Novecento era uno che se tu gli dicevi «Una volta son stato a Parigi », lui ti chiedeva se avevi visto i giardini tal dei tali, e se avevi mangiato in quel dato posto, sapeva tutto, ti diceva "Quello che a me piace, laggiú, è

14 BARICCO, A. Novecento: un monologo. Torino: Angolo Manzoni, 2000a., p. 13. Todas as citações em italiano seguintes são desta mesma edição.

15 BARICCO, A. Novecentos: um monólogo. Trad. Y. A. Figueiredo. Rio de Janeiro: Rocco, 2000b, p.

9. Todas as traduções das citações em italiano seguintes são desta mesma edição. 
aspettare il tramonto andando avanti e indietro sul Pont Neuf, e quando passano le chiatte, fermarmi e guardarle da sopra, e salutare con la mano ».

"Novecento, ci sei mai stato a Parigi, tu?»

"No ».

"E allora...»

"Cioè...sí ».

"Sí cosa?»

"Parigi ».

Potevi pensare che era matto. Ma non era cosí semplice. Quando uno ti racconta con assoluta esattezza che odore c'è in Bertham Street, d'estate, quando ha appena smesso di piovere, non puoi pensare che è matto per la sola stupida idea che in Bertham Street, lui, non c'è mai stato. Negli occhi di qualcuno, nelle parole di qualcuno, lui, quell'aria, l'aveva respirata davvero. (p. 38-39)

Novecentos era um cara que se você lhe dissesse "Uma vez estive em Paris", ele perguntava se você tinha visto tal jardim, se tinha comido em tal lugar, sabia tudo, dizia:

- O que me agrada, naquele lugar, é esperar o pôr-do-sol andando de um lado para o outro da Pont Neuf e, quando passam as chatas, parar e olhar lá de cima, acenando com a mão.

- Novecentos, você nunca esteve em Paris?

- Não.

- E então...

- Isto é... sim.

- Sim, o quê?

- Paris.

Vocês podem pensar que era maluco. Mas, não era assim, simples. Quando alguém lhe conta com exatidão que cheiro existe em Bertham Street, no verão, assim que pára de chover, não pode pensar que é maluco só pela estúpida razão de que, em Bertham Street, ele nunca esteve. Nos olhos de alguém, nas palavras de alguém, ele, aquele ar, ele tinha mesmo respirado. (p. 35-36)

Dessa maneira Novecento conhecia, ou imaginava, o mundo; pelo olhar de outras pessoas. De maneira semelhante o pianista também precisava de várias peças, vários fragmentos, para, em seguida, compor sua própria música. Primeiro ele pedia para que os passageiros da terceira classe cantassem e tocassem suas canções e, após escutá-los, cada um tocando um instrumento musical diferente, o pianista tocava sua “própria música”, ou a música do mundo inteiro, todas juntas.

Giravano storie curiose, anche vere, alle volte, come quella del senatore americano Wilson che si era fatto il viaggio tutto in terza classe, perché era lì che Novecento suonava, quando non suonava le note normali, ma quelle sue, che normali non erano. C'aveva un pianoforte, là sotto, e ci andava di pomeriggio, o la notte tardi. Prima ascoltava: voleva che la gente gli cantasse le canzoni che sapeva, ogni tanto qualcuno tirava fuori una chitarra, o un'armonica, qualcosa, e iniziava a suonare, musiche che venivano da chissà dove... Novecento ascoltava. Poi incominciava a sfiorare i tasti, mentre quelli cantavano o suonavano, sfiorava i tasti e a poco a poco quello diventava un suonare vero e proprio, uscivano dei suoni dal pianoforte - verticale, nero - ed erano suoni dell'altro mondo. C'era dentro tutto: tutte in una volta, tutte le musiche della terra. C'era da rimanere di stucco. (p. 41-42) 
Corriam histórias curiosas, também verdadeiras, às vezes, como aquela do senador americano Wilson que tinha feito toda a viagem na terceira classe, porque era ali que Novecentos tocava, quando não tocava as notas normais. Havia um piano, lá embaixo, e ele ia lá à tarde, ou tarde da noite. Primeiro escutava: queria que as pessoas lhe cantassem as canções que sabiam, de vez em quando alguém aparecia com um violão, ou uma sanfona, alguma coisa e começava a tocar, músicas que vinham quem sabe de onde... Novecentos escutava. Depois, começava a roçar as teclas, enquanto eles tocavam ou cantavam, alisava as teclas e pouco a pouco aquilo ia virando um soar verdadeiro e, realmente, saíam do piano - vertical, preto - e eram sons do outro mundo. Havia tudo, dentro: todas de uma vez, todas as músicas da Terra. Era de se ficar pasmo. (p. 39)

Não gratuitamente o contexto histórico no qual a narrativa está inserida compreende o período de difusão do jazz. Como é notável na primeira referência ao gênero no início do enredo, quando Tim Tooney, o narrador-personagem, conta como foi aceito para tocar na banda do navio.

[...] mi misi a suonare. Lui se ne stette lì a fissarmi senza muovere un muscolo. Aspettò che finissi, senza dire una parola. Poi mi chiese:

"Cos'era?"

"Non lo so».

Gli si illuminarono gli occhi.

"Quando non sai cos'è, allora è jazz ».

Poi fece una cosa strana con la bocca, forse era um sorriso [...]

"Ci vanno matti, per quella musica, lassú ».

Lassú voleva dire sulla nave. E quella specie di sorriso voleva dire che mi avevano preso. (p. 15)

[...] me pus a tocar. Ele ficou ali me olhando, sem mover um músculo. Esperou que eu terminasse, sem dizer uma palavra. Depois, perguntou-me:

- O que era?

- Não sei.

Os seus olhos se iluminaram.

— Quando você não sabe o que é, então é jazz.

Então fez um movimento estranho com a boca, talvez fosse um sorriso [...]

- Estão loucos por aquela música, lá em cima.

Lá em cima significava no navio. E aquele tipo de sorriso significava que tinham me contratado. (p. 11-12)

Nascido nos Estados Unidos no final do século XIX, o jazz tem origem entre os negros americanos, elaborado com elementos africanos, "cantos de trabalho" (work songs) e religiosos (spirituals) dos escravos, de músicas de protesto social (blues), e do ragtime. Alguns de seus elementos característicos são: o uso da sobreposição de ritmos, o livre diálogo entre os instrumentos e a liberdade do solista, que pode exprimir-se na criação de melodias mais ou menos desvinculadas dos temas do conjunto. ${ }^{16}$ Esses

16 ZANICHELLI. Enciclopedia Zanichelli 2006 a cura di Edigeo: dizionario enciclopedico di arti, scienze, tecniche, lettere, filosofia, storia, geografia, diritto, economia. Bologna, 2006. 
elementos transparecem no enredo, em especial este último, característica marcante da música de Novecento, muitas vezes fugindo ao que a banda estava tocando.

Dicevano anche che suonava una musica che non esisteva. Quel che sapevo io era che tutte le volte, prima di iniziare a suonare, li, in sala da ballo, Fritz Hermann, un bianco che non capiva niente di musica ma aveva una bella faccia per cui dirigeva la band, gli si avvicinava e gli diceva sottovoce: "Per favore, Novecento, solo le note normali, okay? ». (p. 32)

Diziam também que tocava uma música que não existia. $\mathrm{O}$ que eu sabia era que todas as ve

zes, antes de começar a tocar, ali no salão de baile, Fritz Hermann - um branco que não entendia nada de música mas tinha um belo tipo para quem dirigia a banda - aproximava-se

dele e lhe dizia em voz baixa:

— Por favor, Novecentos, só as notas normais, okay? (p. 29)

Desse modo era a música de Novecento: inacreditável, única, estonteante, e ao mesmo tempo imprevisível. Os outros músicos componentes da banda ficavam receosos, pois quando ele decidia tocar as suas notas era o fim da linha para a orquestra. Assim, a sobreposição das notas musicais, a livre improvisação e o entrecruzamento dos ritmos reivindicam uma liberdade e impõem-se, ao mesmo tempo, de maneira sedutora e inevitável aos nossos sentidos.

O próprio nome do personagem não seria mera coincidência; Danny Boodmann nos remete a uma paródia do nome de um notável músico conhecido no auge do jazz: o clarinetista Benny Goodman, "o rei do swing". Benjamin David Goodman nasceu em Chicago, no dia 30 de maio de 1909 e faleceu em 13 de junho de 1986. Foi o nono de doze filhos de imigrantes judeus pobres da Polônia. Tornou-se clarinetista e músico de jazz e ficou conhecido como "O Rei do Swing", "Patriarca da Clarineta", "O Professor" e "Mestre do Swing". ${ }^{17}$

Além disso, no enredo, a fama de Danny Boodmann Novecento não demorou a incomodar aquele que se auto-intitulava o melhor pianista e o "inventor do jazz": Jelly Roll Morton. Compositor, pianista e orquestrador de jazz estadunidense que também consta nos arquivos da história do jazz, este foi outro grande músico que embarcou na ficção do Virginian. Jelly Roll Morton, nome artístico de Ferdinand Joseph la Menthe Morton, nasceu em 1885 e faleceu em 1941. Lembrado como pianista e maestro dos Estados Unidos que ajudou a desenvolver o jazz de Nova Orleans ${ }^{18}$, Morton realmente reivindicava ser o inventor do jazz.

\footnotetext{
17 Firestone Ross. Swing, Swing, Swing: The Life and Times of Benny Goodman. Nova York: Norton, 1993. p. 18-19.

18 LONGMAN Dictionary of English Language and Culture. 5. ed. Harlow: Longman, 2002.
} 
Na narrativa, Jelly Roll Morton também desejava ser reconhecido como o inventor do jazz e, ao saber da existência de um pianista que fazia tudo o que quisesse com o piano, tamanho era seu talento e habilidade, tratou de embarcar no Virginian e desafiá-lo a um duelo musical. Novecento estava no Virginian ansioso pela chegada de Jelly Roll Morton, pois não sabia o que significava um duelo e, de fato, tinha acreditado que iria conhecer o inventor do jazz e até adquirir algum aprendizado musical com ele.

Fu d'estate, nell'estate del 1931, che sul Virginian sali Jelly Roll Morton. [...]

Alle 21 e 37 del secondo giorno di navigazione, col Virginian spedito a 20 nodi sulla rotta per l'Europa, Jelly Roll Morton si presentò nella sala da ballo di prima classe, elegantissimo, in nero. Tutti sapevano benissimo cosa fare. I ballerini si fermarono, noi della band posammo gli strumenti, il barman versò un whisky, la gente ammutoli. Jelly Roll prese il whisky, si avvicinò al pianoforte e guardò negli occhi Novecento. Non disse nulla, ma quello che si sentì nell'aria fu: "Alzati da lì».

Novecento si alzò.

"Lei è quello che ha inventato il jazz, vero?"

" Già. E tu sei quello che suona solo se ha l'Oceano sotto il culo, vero?"

"Già ». (p. 40-45)

Foi no verão, no verão de 1931, que Jelly Roll Morton subiu ao Virginian.

$[\ldots]$

Às 21:37 h do segundo dia de navegação, com o Virginian andando a vinte nós na rota para a Europa, Jelly Roll Morton se apresentou no salão de baile da primeira classe, elegantíssimo, de preto. Todos sabiam muito bem o que fazer. Os dançarinos pararam, nós da banda, pousamos os instrumentos, o barman serviu um uísque, as pessoas se amontoaram. Jelly Roll tomou o uísque, aproximou-se do piano e olhou Novecentos no olhos. Não disse nada, mas o que se ouviu no ar foi "levanta daí".

Novecentos levantou-se.

- O senhor é aquele que inventou o jazz, certo?

— Isso. E você é aquele que só toca se tem o oceano embaixo do cu, certo?

- Isso. (p. 38-42)

Primeiro Jelly Roll Morton sentou-se ao piano e iniciou com um ragtime. Ele tocava tão suavemente que o cigarro que havia colocado na beira do piano ia se consumindo, porém as cinzas não caíam, estavam ali. Depois foi a vez de Novecento, tocou uma canção infantil Torna indietro paparino; não era uma demonstração de habilidade, mas era uma canção que tinha ouvido de um imigrante e que lhe agradava, lhe comovia. Jelly Roll, decepcionado, atacou com um blues. Executou com pompa e leveza, que segundo Tim, era como se todo o algodão de todos os negros do mundo estivesse ali e ele o recolhesse, com aquelas suaves notas. E Novecento, também emocionado, respondeu tocando o mesmo blues que tinha acabado de ouvir; numa série de acordes lentíssimos, estranhos, da maneira que tinha organizado na sua cabeça e sentia prazer em tocar. Resposta que irritou ainda mais Jelly Roll que saltou ao piano e 
desandou a tocar em grande velocidade, sem errar sequer uma nota; era como um jogo de prestígios. Arrancou gritos e aplausos do salão. Finalmente, Novecento entendeu que se tratava de uma disputa ao piano, e respondeu à altura: pegou um cigarro emprestado do amigo Tim e o apoiou na beira do piano, apagado; em seguida, tocou uma música com acordes fortíssimos, parecendo ter cem mãos. Ao final, pegou o cigarro e aproximou-o das cordas do piano e, com um ligeiro chiado, o cigarro estava aceso. "Gentilmente" ofereceu-o a Jelly Roll Morton e disse:

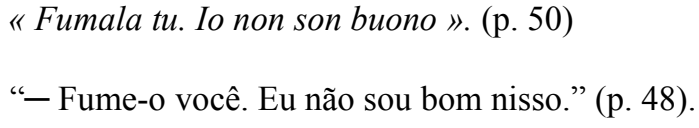

Foi uma loucura, uma apoteose de aplausos. Morton passou o resto da viagem fechado em sua cabine e desceu do Virginian ao chegarem ao próximo porto. Não queria mais saber daquilo e de Novecento, somente queria saber de voltar para América; em outro navio.

Todas as histórias ficcionais passadas no Virginian nos transportam a uma viagem com cenários referentes a momentos históricos e marcantes do século $\mathrm{XX}$; a história do Novecento. Notemos como o Virginian transporta todas elas de uma só vez. O transatlântico não somente veicula informações, histórias de vida ficcionais, como também se refere a fatos históricos e personalidades que realmente existiram. Dessa maneira, significa ele mesmo tais informações e histórias. Ao mesmo tempo comporta, transporta e significa.

No fim da linha do bonde, de Machado de Assis, e desativado o transatlântico Virginian, de Alessandro Baricco, convido o leitor a finalizarmos nosso passeio: saltamos e desembarcamos. Tomemos uma pequena distância e notemos que tanto no bonde como no transatlântico pudemos realizar a leitura desses meios de transportes como "veículos alegóricos". Em Passagens de Bond, com Machado, partimos da consideração do bonde por Andrade (1996) como o transporte alegórico da própria crônica, analisando a ambivalência desta como forma de produção jornalística, que ao ligar-se ("estar bonded") e ao desligar-se (como é o caso do burro) à nova tecnologia, revelou-se no transporte que se fez alegórico da própria crônica como elo, ou liga locomotora. No bonde pudemos notar o alto preço da passagem no transporte dos passageiros do fim do século XIX e início do XX, passagem do ambiente rural para o urbano. Pois tinham de aderir ao ritmo frenético imposto pela modernidade e exposto 
pelo advento da eletricidade nos bondes elétricos. Fato que equiparou o ser humano ao burro, e assim o desejava, já que ele já não precisaria de muito pensar, bastaria aderir ao novo bonde da modernidade. $\mathrm{O}$ bonde se fez aqui o veículo alegórico transportando os passageiros, as informações referentes ao contexto histórico da chegada da eletricidade; o próprio bonde como transporte coletivo significou o veículo alegórico da história, ou seja, é a história.

No Virginian tivemos a diferença no tocante ao alto preço que os passageiros do século $\mathrm{XX}$, o Novecento italiano, tiveram de pagar referente às conseqüências resultantes dos fatos históricos do período entre guerras, tendo de se deslocar da Europa, em busca de condições melhores de vida, para a América. E, principalmente, nas formações discursiva e musical como observamos na história ficcional do pianista Danny Boodmann T. D. Lemon Novecento, constituída por fragmentos discursivos e musicais das pessoas que conhecera no navio para depois formar seu mapa do mundo e sua música, que não eram particulares, mas sim de todo o mundo. Assim, pudemos interpretar o Virginian como o veículo que transportava não só os passageiros como as informações: dos passageiros e do contexto histórico do século XX, além de significar essa história. 


\section{REFERÊNICAS}

ANDRADE, Ana Luiza. Passagens de Bond, com Machado. Travessia 33. Revista de Literatura da Pós-Graduação, EDUFSC, 1996.

BARICCO, A. Novecento: un monologo. Torino: Angolo Manzoni, 2000a.

Novecentos: um monólogo. Trad. Y. A. Figueiredo. Rio de Janeiro: Rocco, $2000 b$.

BENJAMIN, W. Origem do drama barroco alemão. Trad. Sérgio Paulo Rouanet. São Paulo: Braziliense, 1984.

BUCK-MORSS, Susan. Dialética do Olhar. Walter Benjamin e o Projeto das Arcadas ou Passagens. Trad. Ana Luiza Andrade. BH/ Chapecó: Ed. UFMG/ Argos, 2002.

FIRESTONE, Ross. Swing, Swing, Swing: The Life and Times of Benny Goodman. Nova York: Norton, 1993. p.18-19.

LONGMAN Dictionary of English Language and Culture. 5. ed. Harlow: Longman, 2002.

ZANICHELLI. Enciclopedia Zanichelli 2006 a cura di Edigeo: dizionario enciclopedico di arti, scienze, tecniche, lettere, filosofia, storia, geografia, diritto, economia. Bologna, 2006.

\section{SITES CONSULTADOS}

http://www.cce.ufsc.br/ nupill/literatura/quinze.html

http://www.cce.ufsc.br/ nupill/literatura/semana.html

http://bluelester.no.sapo.pt/jazz/historia.htm

http://rascunho.rpc.com.br/ 